Session 2793

\title{
An Undergraduate Research Project: Experimental Investigation of Drag Reduction for a Cylinder with an Attached Fin
}

\author{
William Cook and Said Shakerin ${ }^{1}$ \\ Lawrence Livermore National Laboratories / University of the Pacific \\ Livermore, CA / Stockton, CA \\ wcook@llnl.gov / sshakerin@uop.edu
}

Key words: drag reduction, wind tunnel, load cell, fin, undergraduate research

\begin{abstract}
An example of an undergraduate research project carried out in the area of fluid mechanics is reported in this paper. This project can also be used as a laboratory demonstration, and can easily be reproduced in departments elsewhere. Specifically, an experimental investigation was conducted to determine how drag is affected when a longitudinal fin is attached to the trailing edge of a cylinder. Models were mounted normal to the flow direction in an open loop wind tunnel. A strain gage-based load cell was designed, fabricated and calibrated to measure the drag, and it was mounted outside the test section just beneath the wind tunnel floor. The experimental variables included the air speed and fin length, creating a range of Reynolds number from $22 \times 10^{3}$ to $10^{5}$ and fin length to cylinder radius ratio of 0.25 to 2 . Tests with cylinder without fin were also performed to obtain base-line data for comparison. Results indicate that the addition of fin causes a reduction in drag compared to a cylinder without a fin. Future research direction is outlined.
\end{abstract}

\section{Introduction}

Undergraduate engineering students at the University of the Pacific are encouraged to participate in research as a part of their academic requirements, and receive up to 4 credit hours for it. The experimental work reported here was carried out as an undergraduate research project while the first author was pursuing his B.S. degree in the Department of Mechanical Engineering. Undergraduate research activity has recently received attention among engineering educators. Reference 1 provides a short article on the benefits of involving undergraduate students in research projects. These benefits include, but are not limited, to an opportunity for students to learn about project planning and management, and to improve their writing skill in terms of producing a technical paper worthy of publication. Such experience is a definite plus that can be proudly added to their resumes.

\footnotetext{
${ }^{1}$ Corresponding author

"Proceedings of the 2002 American Society for Engineering Education Annual Conference \& Exposition Copyright (C) 2002, American Society for Engineering Education”
} 
The general topic of interest in this research is drag reduction techniques in external flow. And, the ultimate goal is to come up with a simple technique to reduce the overall drag of high speed bicycles. For a quick review of the general subject of drag reduction, see reference 2, while references 3 and 4 provide more details. Basically, in external flow, flow suction and surface modification, among other techniques, have proven to reduce the overall drag. Through literature search it was found that drag reduction research corresponding to the bicycle application is limited. As a starting point, we decided to work with a simple model, namely a cylinder.

Thus, the purpose of this experiment was to test the hypothesis that drag on a cylinder oriented normal to the airflow direction would be reduced by a longitudinal fin attached to the downstream side. The basis of the hypothesis is that a finned cylinder would simulate the shape of a streamlined body, as schematically shown in Figure 1.

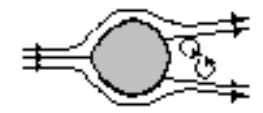

(1)

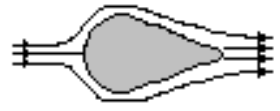

(b)

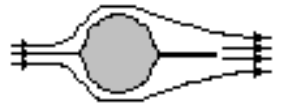

(c)

Figure 1. Comparison of flow patterns around (a) cylinder, (b) streamlined body, and (c) finned cylinder, viewed from the top.

\section{Experimental Setup}

\subsection{Equipment}

Wind tunnel - The wind tunnel was an open circuit type with a maximum wind speed of $150 \mathrm{mph}$. The test section was a 12" square cross-section, 30" long. Test section pressure was measured by a manometer attached to the test section. Flow velocity was varied by adjusting fan motor speed by means of a rheostat.

Model - The model was a finned cylinder mounted vertically at the center of the test section atop a load cell, Figure 2. The cylinder extended the full height of the test section. A slot was machined lengthwise at the trailing edge of the cylinder to accept the fins. The fins were held in place by 2 set screws.

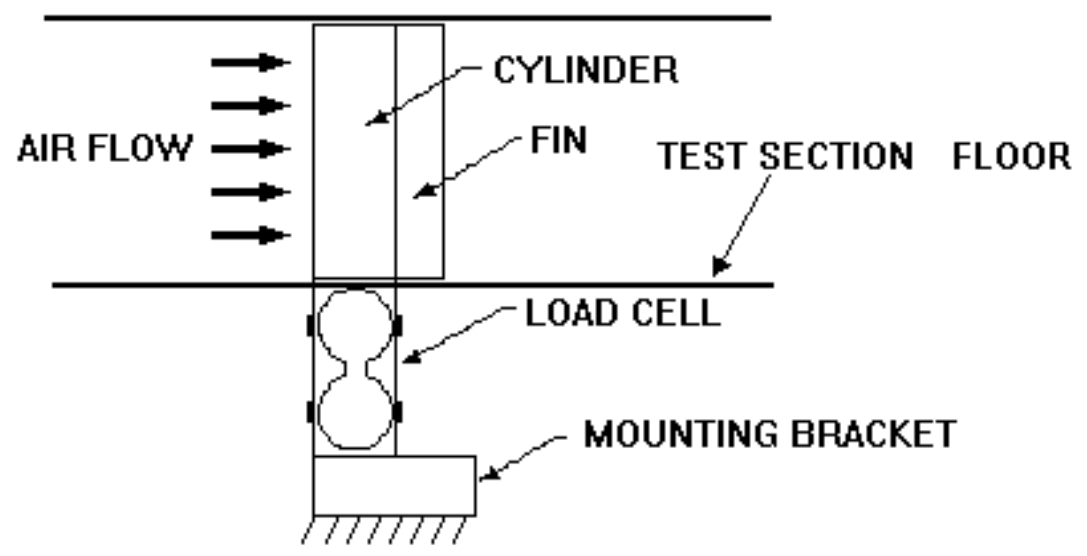

Figure 2. Load cell and model schematic 
Load cell - The load cell was a strain gage based "binocular" type (Figure 3) placed between a stiff mounting bracket outside of the test section and the model inside. The binocular descriptive refers to the shape of the spring element. Two holes were bored through, as shown, leaving thin webs in four locations. Four strain gages (Measurements Group, Inc. model CEA 13-240UZ120) were bonded to the outside surfaces adjacent to the webs. Drag on the cylinder is transmitted to the spring element in the direction shown, placing gages $1 \& 4$ in compression and gages $2 \& 3$ in tension.

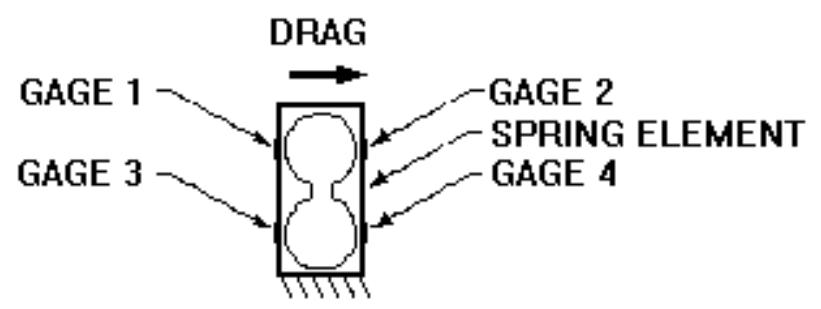

Figure 3. Strain gage placement on the load cell.

The gages were connected to a full Whetstone bridge incorporated into a strain indicating instrument (Measurements Group, Inc. Model \# P-3500). The instrument included a digital readout in units of microstrain $(\mu \varepsilon)$. This arrangement resulted in a bridge constant of four with full temperature compensation. In addition, this type of connection produces the highest output and combines insensitivity to applied moments and transverse loads with high sensitivity to drag. The binocular geometry provides a minimum of shape distortion for nominal loads. A full description of various load cell design characteristics can be found in reference 5 .

Load Cell Calibration Fixture - The load cell was calibrated in situ with the cylinder attached as shown in Figure 4. The calibration fixture support was movable allowing for attachment to the cylinder at different points along the height. Three calibrations were performed in $0.980 \mathrm{~N}$ increments from $0.980 \mathrm{~N}$ to $9.800 \mathrm{~N}$. One calibration each was performed at the top, center, and bottom of the cylinder. The results of the three calibrations confirmed the insensitivity of the load cell to applied moments. The resulting calibration constant was $110.2 \mu \varepsilon / \mathrm{N}$.

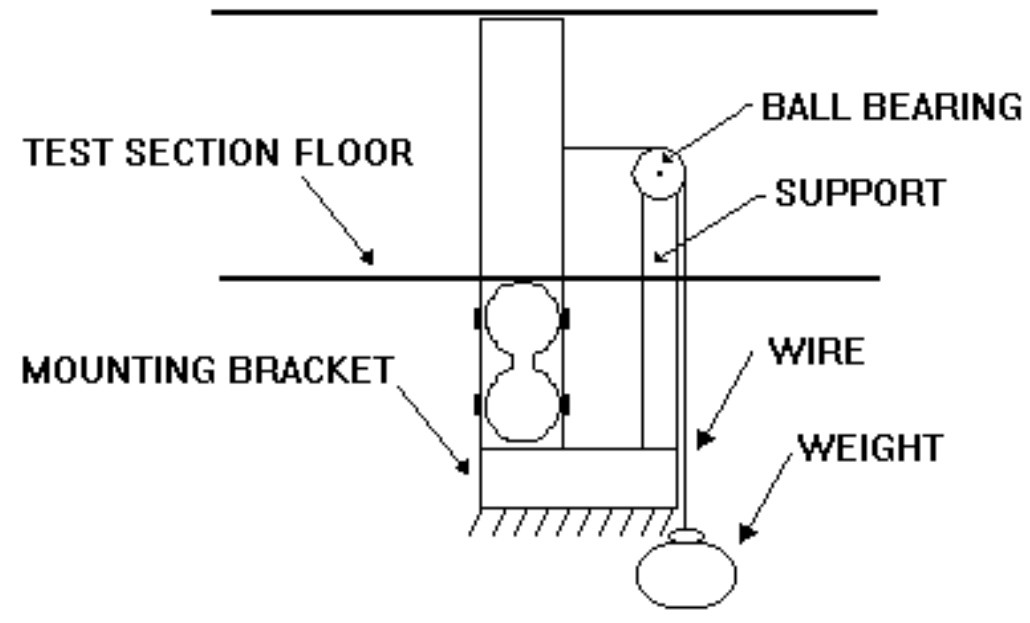

Figure 4. Calibration fixture. 


\subsection{Procedure}

The experiment consisted of six (6) runs, one with no fin and one each with fins of lengths of $1 / 4$, $1 / 2,1,3 / 2$, and 2 times the radius of the cylinder. Each run began by zeroing the strain gage readout at zero wind speed. Flow was initiated and strain was recorded at manometer increments of $1 / 2$ ". A total of twenty manometer/strain data pairs were recorded from $1 / 2$ " to 10 " corresponding to velocities of 13 to $58 \mathrm{~m} / \mathrm{s}$. The pressure was then increased above 11 " and returned to 10". Twenty (20) more data pairs were recorded in decreasing increments of 1/2" and the flow was stopped. This process was repeated once for a total of forty (40) strain measurements, 20 increasing and 20 decreasing, for each fin.

This project can also be used as a laboratory demonstration, and can easily be reproduced in departments elsewhere.

\section{Mathematical Relationships ${ }^{2}$}

For a cylinder:

$$
\boldsymbol{R e}=\frac{\mathrm{Vd} \rho}{\mu}
$$

Where:

$$
\begin{aligned}
& \operatorname{Re}=\text { Reynolds number } \\
& V=\text { flow velocity } \\
& d=\text { diameter of cylinder } \\
& \rho=\text { density of fluid } \\
& \mu=\text { kinematic viscosity of fluid }
\end{aligned}
$$

And:

$$
C_{D}=\frac{2 F_{D}}{A \rho V^{2}}
$$

Where:

$$
\begin{aligned}
& C_{D}=\text { drag coefficient } \\
& F_{D}=\text { drag }
\end{aligned}
$$$$
\mathrm{A}=\text { frontal area }
$$

With respect to nomenclature shown in Figure 5, Bernoulli's equation states:

$$
\frac{\mathrm{P}_{1}}{\rho_{\text {air }}}+\frac{\mathrm{V}_{1}^{2}}{2}=\frac{\mathrm{P}_{2}}{\rho_{\text {air }}}+\frac{\mathrm{V}_{2}^{2}}{2}
$$

Where:

Solving for $\mathrm{V}_{2}$ :

$$
\begin{aligned}
& \mathrm{P}_{1}=\text { atmospheric pressure } \\
& \mathrm{P}_{2}=\text { pressure inside of test section } \\
& \mathrm{V}_{1}=\text { velocity of air outside of tunnel } \\
& \mathrm{V}_{2}=\text { velocity of air outside inside of test section } \\
& \rho_{\text {air }}=\text { density of air }
\end{aligned}
$$

\footnotetext{
${ }^{2}$ All relationships given in this section can be found in any undergraduate level fluid mechanics textbook.

"Proceedings of the 2002 American Society for Engineering Education Annual Conference \& Exposition Copyright $\left({ }^{\circ}\right.$ 2002, American Society for Engineering Education”
} 


$$
\mathrm{V}_{2}=\sqrt{\frac{2}{\rho_{\text {air }}}\left(\mathrm{P}_{1}-\mathrm{P}_{2}\right)}=\sqrt{\frac{2 \Delta \mathrm{P}}{\rho_{\text {air }}}}
$$

$\Delta \mathrm{P}$ is defined as:

$$
\Delta \mathrm{P}=\gamma_{\text {manometer }} \Delta \mathrm{h}=\rho_{\text {water }} \mathrm{SG}_{\text {manometer }} \mathrm{g} \Delta \mathrm{h}
$$

Where:

$$
\begin{array}{ll}
\gamma_{\text {manometer }} & =\text { specific weight of the manometer fluid } \\
\rho_{\text {water }} & =\text { density of water } \\
\mathrm{SG}_{\text {manometer }} & =\text { specific gravity of manometer fluid } \\
\Delta \mathrm{h} & =\text { the manometer reading }
\end{array}
$$

Substituting :

$$
\mathrm{V}_{2}=\sqrt{\frac{2 \mathrm{~g} \rho_{\text {water }} S G_{\text {manometer }} \Delta \mathrm{h}}{\rho_{\text {air }}}}=\sqrt{\frac{2 \mathrm{~g} \rho_{\text {water }} S G_{\text {manometer }}}{\rho_{\text {air }}}} \sqrt{\Delta \mathrm{h}}
$$

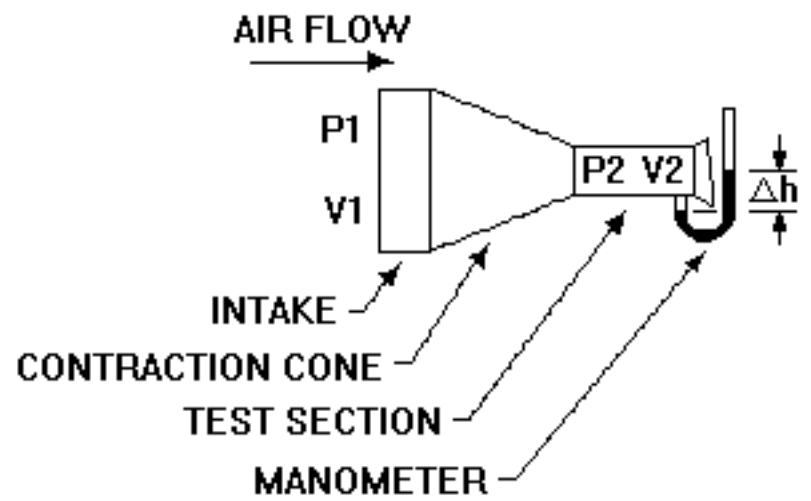

Figure 5. Wind tunnel pressure measurement schematic.

\section{Results}

The experiment was conducted in an air-conditioned laboratory with an ambient temperature of $74^{\circ} \mathrm{F}$ over a period of four hours. Figure 6 shows the processed data in graphical form. 


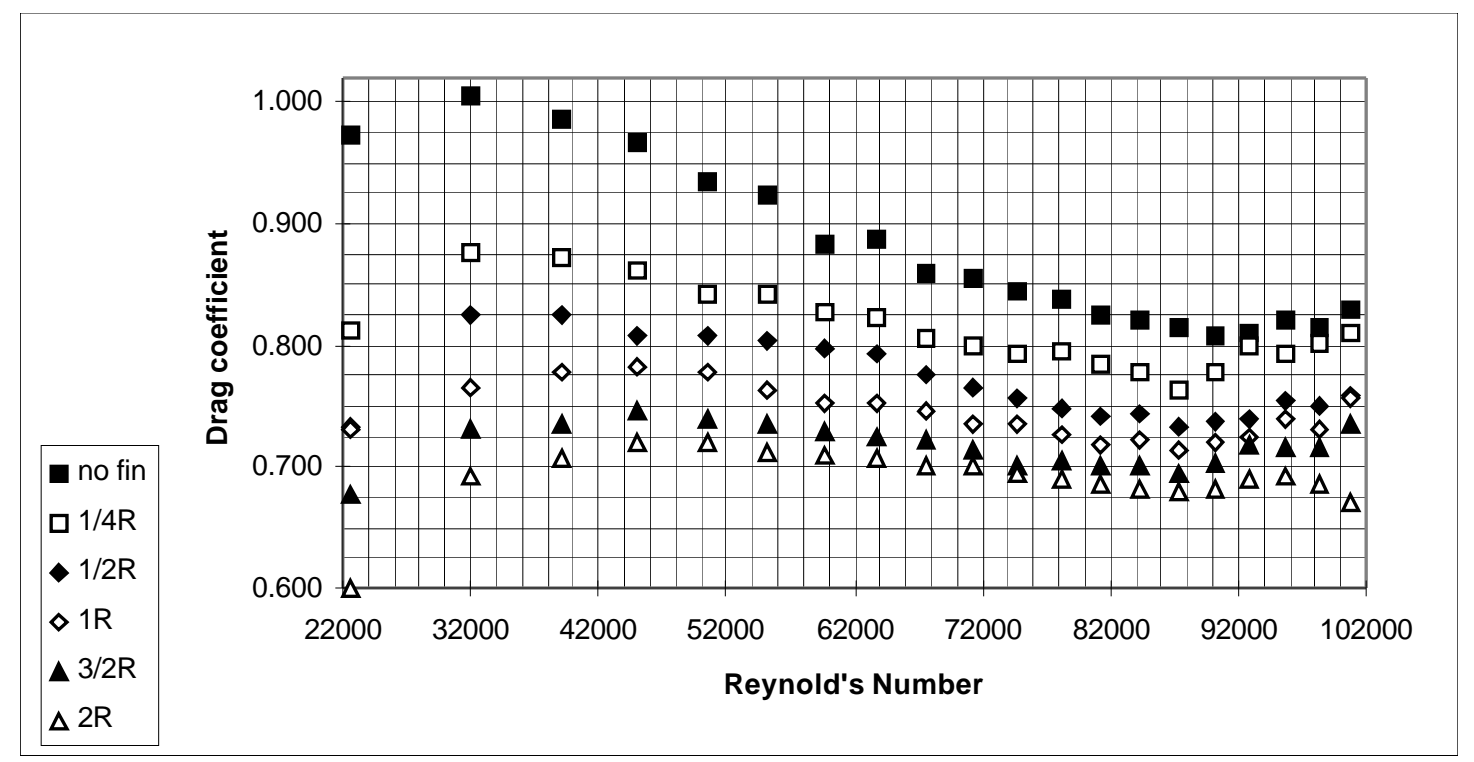

Figure 6. Drag coefficient for cylinders with and without fin. Fin lengths in terms of cyclinder radius are given on the left of the graph.

At each manometer setting, the flow was allowed to develop so that the strain indicator reading could stabilize. In spite of this, the spread of the readings was significant in some cases (up to $30 \%$ for the $3 / 2 \mathrm{R}$ fin at the lowest Reynolds number). Transverse oscillations of the cylinder were observed but they did not correlate with strain reading stability. The oscillations increased with wind speed up to a point and then settled down at higher speeds. The maximum occurred at different speeds for different fin lengths. Since the oscillations did not affect strain reading stability they were not studied further.

\section{Discussion}

Inspection of Figure 6 points out two trends. First, the drag is consistently reduced with increasing fin lengths for all Reynolds numbers. Second, the rate of reduction decreases with increasing fin length for all Reynolds numbers. In order to assess the significance of these trends a determination of the level of uncertainty is required.

For a function of multiple variables:

$$
f\left(\mathrm{x}_{1}, \mathrm{x}_{2}, \mathrm{~K}, \mathrm{x}_{\mathrm{n}}\right)
$$

The uncertainty $(\mathrm{U})$ is given by:

$$
\mathrm{U}_{\text {total }}(f)=\left[\left(\frac{\partial f}{\partial_{\mathrm{x}_{1}}} \mathrm{U}_{\mathrm{x}_{1}}\right)^{2}+\left(\frac{\partial f}{\partial_{x_{2}}} U_{x_{2}}\right)^{2}+\Lambda+\left(\frac{\partial f}{\partial_{\mathrm{x}_{\mathrm{n}}}} \mathrm{U}_{\mathrm{x}_{\mathrm{n}}}\right)^{2}\right]^{1 / 2}
$$

The total uncertainty of drag is obtained by rewriting Eqn. (2) in terms of strain indicator $(\mu \varepsilon)$ and manometer $(\Delta \mathrm{h})$ readings, simplifying, and assigning values for the constants as follows: 


$$
\mathrm{C}_{\mathrm{D}}=\frac{2 \mathrm{~F}_{\mathrm{D}}}{\mathrm{A} \rho_{\text {air }} \mathrm{V}^{2}}=\frac{(2)(\text { calibration factor })(\mu \varepsilon)}{\mathrm{A} \rho_{\text {air }}\left(\frac{(2)(\mathrm{g})\left(\rho_{\text {water }}\right)\left(\mathrm{SG}_{\text {manomater }}\right)}{\rho_{\text {air }}}\right) \Delta \mathrm{h}}
$$

Assuming all values except strain and manometer readings are constant and substituting appropriate values yields:

$$
\mathrm{C}_{\mathrm{D}}=\frac{(0.009 \mathrm{~N} / \mu \varepsilon)(\mu \varepsilon)}{\left(.00762 \mathrm{~m}^{2}\right)\left(9.81 \mathrm{~m} / \mathrm{s}^{2}\right)\left(1000 \mathrm{~kg} / \mathrm{m}^{3}\right)(0.826)(\Delta \mathrm{h})}=1.47 \times 10^{-4} \frac{\mu \varepsilon}{\Delta \mathrm{h}}
$$

Applying Eqn. (5) to Eqn. (6) gives:

$$
\mathrm{U}_{\text {total }}\left(\mathrm{C}_{\mathrm{D}}\right)=\left[\left(\frac{1.47 \times 10^{-4}}{\Delta \mathrm{h}} \mathrm{U}_{\mu \varepsilon}\right)^{2}+\left(\frac{\left(1.47 \times 10^{-4}\right) \mu \varepsilon}{\Delta \mathrm{h}^{2}} \mathrm{U}_{\Delta \mathrm{h}}\right)^{2}\right]^{1 / 2}
$$

Equation (7) was applied to each set of readings using one standard deviation as the uncertainty of the strain reading $\left(\mathrm{U}_{\mu \varepsilon}\right)$ and 0.05 " $(0.00127 \mathrm{~m})$ as the uncertainty of the manometer reading $(\mathrm{U}$ $\Delta_{\mathrm{h}}$ ). Figure 7 is a plot of these results for three fin lengths. This plot shows significant differentiation in the range of $\operatorname{Re}=32000-100000$. Below $\operatorname{Re}=32000$, the flow was not fully developed affecting the stability of the strain indicator readings. Above $\mathrm{Re}=92000$, the increasing uncertainty is a reflection of the fact that the strain was approaching the linear range limitations of the gages.

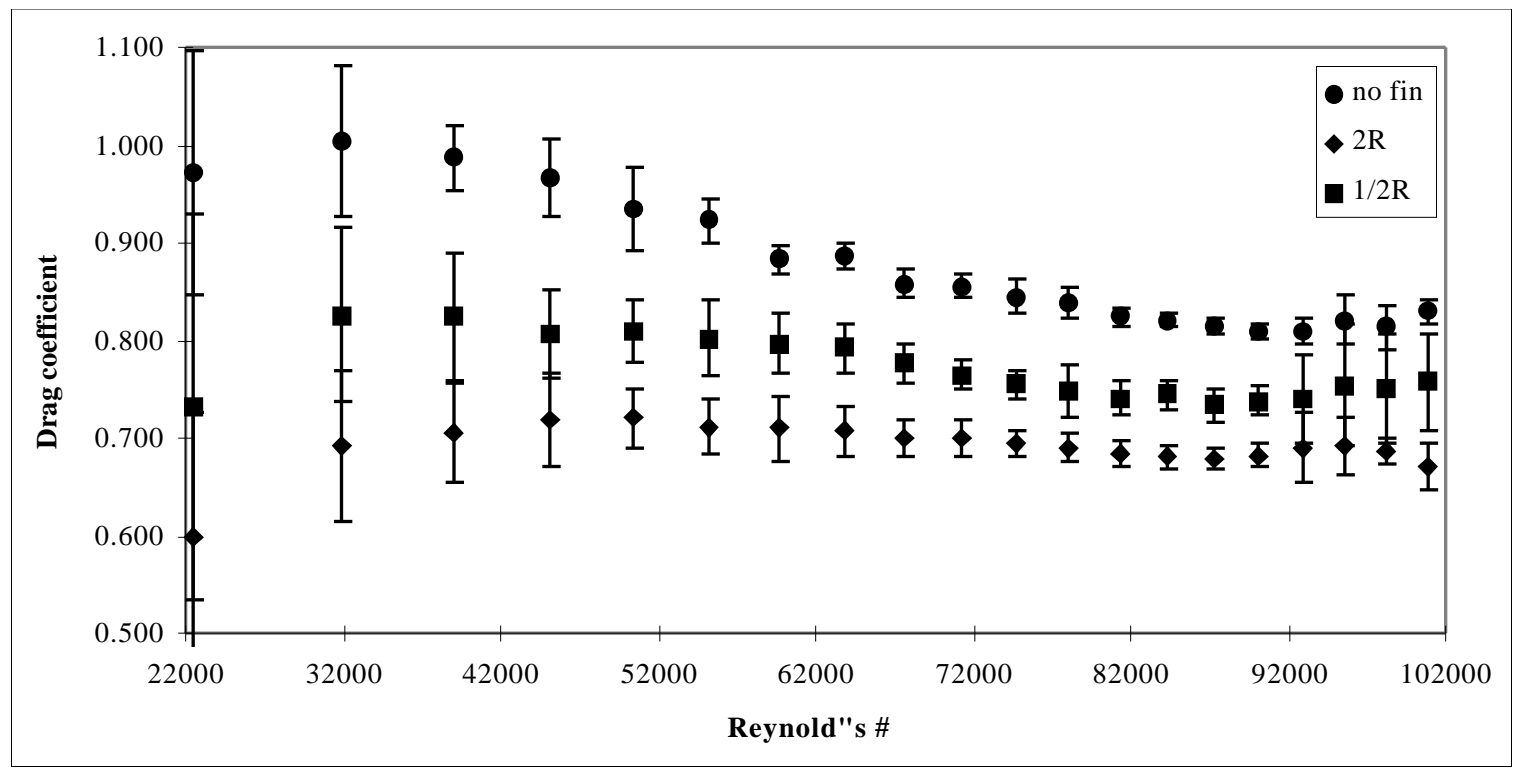

Figure 7. Uncertainty for three representative fin lengths.

Figure 8 shows the percentage reduction in drag as a function of Reynolds number for the $2 \mathrm{R}$ fin with respect to no fin. 


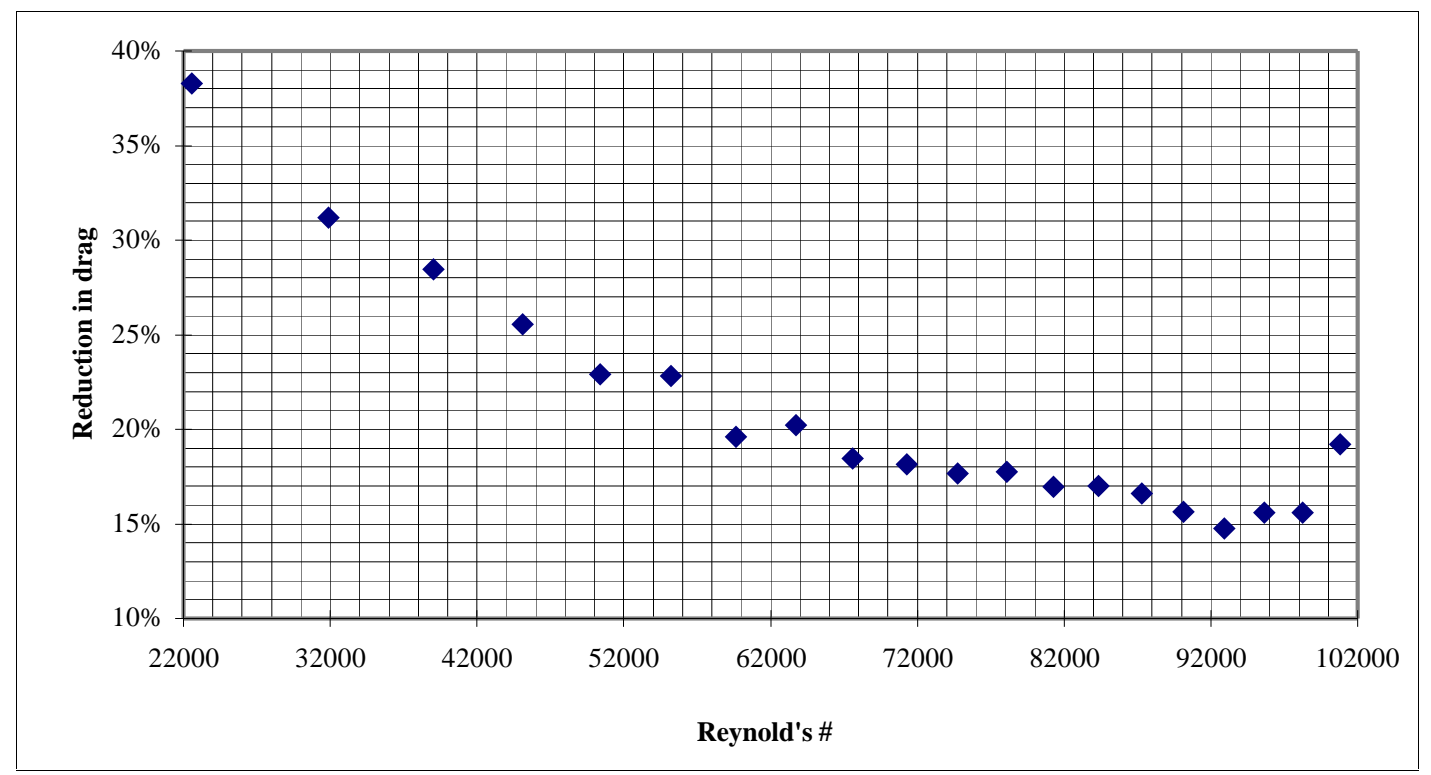

Figure 8. Percent reduction in drag for 2R fin with respect to no fin.

Caution should be used when projecting these results onto real world situations. Comparisons are valid only for models of similar Reynolds numbers. Although the aforementioned transverse oscillations were not significant in these measurements, they may be in real world situations. A number of improvements in the experimental apparatus could significantly reduce the uncertainty. Redimensioning the load cell and using gages with a greater range would increase the sensitivity of this component. This, coupled with an electronic data acquisition system that utilizes automatic time averaging, would decrease the problem of instability in the strain readings. An electronic pressure transducer would reduce the uncertainty associated with reading a glass tube manometer.

\section{Future Research}

The next step in this research would be to investigate its potential for use in drag reduction for a recumbent bike. The recumbent bike is also known as human powered vehicle (HPV). The American Society of Mechanical Engineers sponsors an annual student competition in HPV design. The competition includes static judging of the design/construction of HPV plus sprint and endurance races.

Designers of HPV often use a canopy or shell as a fairing to cover the HPV to reduce the overall drag, and hence, to increase the speed. This is of particular significance to the result of the sprint race. The addition of a full-size fairing usually causes complications to the design and operation of the HPV. Instead of a full-size fairing, a possible scheme might be to just add a fin behind the seat of the HPV. If the fin proves to be useful in reducing the overall drag, as demonstrated in this paper for a cylinder, then it would be advantageous in comparison with a full-size fairing currently used in HPVs that compete in sprint races. Full-scale tests with an actual HPV fitted with a fin should be carried out to verify this speculation.

"Proceedings of the 2002 American Society for Engineering Education Annual Conference \& Exposition Copyright (C) 2002, American Society for Engineering Education” 


\section{Conclusions}

Addition of a trailing fin to a cylinder mounted normal to the direction of flow significantly reduces drag in the range of Reynolds numbers from 20000 - 100000. The fin addition reduces the separation zone and thus reduces the drag. The reduction increases with fin length but the amount of reduction diminishes with fin length. The percent reduction is greatest at the low end of this range and decreases with increasing Reynolds number. Periodic transverse oscillations also occur in this range at different Reynolds numbers for different fin lengths. The result of this project may be extended to reduction of drag for recumbent bicycles.

\section{References}

1. Wankat, P., and Oreovicz, F., "Starting Young," ASEE Prism, Vol. 11, No. 6, p. 40, Washington, 2002.

2. Summary on drag reduction techniques: www.aerodyn.org/drag/vdrag.html.

3. Sellin, R. H. J., and Moses, R. T., “Drag Reduction in Fluid Flows: Techniques for Friction Control," Ellis Horwood, Ltd., Chichester, 1989.

4. Choi, K. S., Prasad, K. K., and Troung, T. V., "Emerging Techniques in Drag Reduction,” Mechanical Engineering Publication, Ltd., London, 1996.

5. "Strain Gaged Based Transducers," Second Edition, Measurements Group, Inc., Raleigh, North Carolina, 1988.

\section{Biographies}

WILLIAM COOK is a 1999 graduate of the University of the Pacific with a Batchelor's Degree in Mechanical Engineering. He is currently working as a project engineer on the National Ignition Facility (NIF) at Lawrence Livermore National Laboratory. NIF is the world's largest laser system. Responsibilities include oversight of the design, fabrication, and procurement of laser beam transport infrastructure components for the Target Chamber building of NIF.

SAID SHAKERIN is a professor of Mechanical Engineering at the University of the Pacific. He is a registered professional engineer in California, and earned his Ph.D. from Colorado State University in 1986. He served as department chairman from 1995 to 1998. His teaching encompases thermal/fluid, instrumentation, and engineering design. Current scholarly activities include design of special effect fountain, design for disabled, and educational innovation. He is a recipient of a DOE-AWU sabbatical fellowship and DOW-ASEE Outstanding Educator Award. 